\title{
JUSTICIA CONSTITUCIONAL Y ARGUMENTACIÓN JURÍDICA
}

\author{
Pedro P. Grández CaStro*
}

RESUMEN: En el presente ensayo, el autor propone la necesidad de asumir una teoría exigente de argumentación jurídica como herramienta de legitimación en la actuación de los tribunales y cortes constitucionales, en un contexto en el que estos juegan un importante papel en la definición de los conflictos jurídicos y en la adjudicación de los derechos. En esta tarea, que no es solo de técnica jurídica, resulta de especial importancia identificar las preconcepciones o "precompromisos" que forman parte irreducible de la discreción judicial que acompaña a las tareas de adjudicación constitucional. En tal sentido, el autor identifica tres "actitudes" o ideologías que condicionan las concreciones interpretativas de la Constitución: una primera, orientada a la fidelidad al texto; una segunda, que expresa un escepticismo frente a los límites semánticos; y una tercera, que intenta intermediar entre ambas posturas, al aceptar el texto como punto de partida de todo proceso de argumentación constitucional que, no obstante, debe responder de modo central al problema planteado, buscando siempre una respuesta racional a un caso constitucional en el que no es posible prescindir de la razón práctica y de los compromisos morales. El autor asigna un rol central a la teoría de la argumentación racional en esta dirección.

PALABRAS CLAVE: Justicia constitucional - Tribunal Constitucional argumentación jurídica-preconcepciones.

\footnotetext{
Abogado por la Universidad Nacional Mayor de San Marcos (Perú). Magíster en Política Jurisdiccional por la Pontificia Universidad Católica del Perú. Diplomado en Gobernabilidad y Desarrollo Institucional por la Universidad Alcalá de Henares y el Instituto Nacional de Administración Pública de Espańa (INAP). Profesor Ordinario de la Facultad de Derecho de la Universidad Nacional Mayor de San Marcos. Profesor en la Escuela de Graduados de la Pontifica Universidad Católica del Perú y en la Escuela de Postgrado de la Universidad de San Martín de Porres. Director Ejecutivo del Centro de Estudios Constitucionales del Tribunal Constitucional del Perú. Correo electrónico: pgrandez@tc.gob.pe Fecha de recepción: 30 de noviembre de 2009.

Fecha de aprobación: 18 de diciembre de 2009.
} 


\section{CONSTITUTIONAL Justice AND LEgAL REASONING}

ABSTRACT: In this essay the author presents the need to assume a theory that demands legal debate as a means of legitimation in the proceedings of constitutional courts and tribunals, given they play an important role in the definition of legal conflicts and the assignment of rights. In this task it is important to identify the preconceptions that inarguably conform the judicial discretion that comes together with the constitutional judgment. The author identifies three "attitudes" or ideologies that condition the interpretations of the Constitution as a matter of fact: first, oriented to the accuracy to the text. Second, one that is skeptical in the face of the semantic limits. And third, an intermediate between both positions, as it accepts the text as a starting point of the whole process of constitutional argumentation, which must respond to the proposed problem, always searching for a rational result to a constitutional case where it is impossible not to consider the practical reasoning and the moral commitments. The author assigns a core role to the rational argumentation theory.

KEY WORDS: Constitutional Justice - Constitutional Court - legal reasoning - preconception.

\section{1) PRemisa: La "MARCHA TRIUNFAL" De la JUSTICIA CONSTITUCIO- NAL Y SUS DESAFÍOS}

La significativa presencia de la justicia constitucional en las democracias contemporáneas viene generando una serie de transformaciones no solo en el ámbito propio del Derecho Constitucional, sino que sus consecuencias se expanden y tocan la propia estructura de las normas jurídicas y de la teoría del Derecho en general ${ }^{1}$. Peter Häberle ${ }^{2}$ ha calificado

Sobre la incidencia del modelo del constitucionalismo en la teoría del Derecho puede verse, entre otros muchos trabajos en castellano: ZaGrebelsky, Gustavo (1995). El derecho dúctil, Ley, derechos y Justicia. Traducción de Marina Gascón. Madrid: Trotta; Prieto Sanchís, Luis (1999). Constitucionalismo y positivismo. México: Fontamara; SASTRE, Santiago (1999). Ciencia juridica positivista y neoconstitucionalismo. Madrid: McGraw-Hill Interamericana de España; Carbonell Sánchez, Miguel (2003). Neoconstitucionalismo(s). Madrid: Trotta; Carbonell Sánchez, Miguel (2007). Teoria del neoconstitucionalismo: ensayos escogidos. Madrid: Trotta; Ferrajoli, Luigi / Moreso, Josep Joan / Atienza, Manuel (2008). La teoría del derecho en el paradigma constitucional. Madrid: Fundación Coloquio Jurídico Europeo; Atienza Rodríguez, Manuel (2007). "Constitución y argumentación". Anuario de Filosofía del Derecho. No 24, pp. 197-228. Un diálogo reciente entre dos profesores de Filosofía del Derecho da cuenta de la actualidad del debate en Espańa; "Imperio de la Ley y Constitucionalismo: un diálogo entre Manuel Atienza y Francisco Laporta" (2008), El Cro- 
de "marcha triunfal" con alcance "mundial" a la proyección de la justicia constitucional en las actuales democracias. En la misma dirección, Martín Shapiro ha anotado que este entusiasmo por la justicia constitucional viene en realidad auspiciado por el "entusiasmo global por los derechos" 3 que se ha suscitado en todo Europa en la segunda mitad del siglo XX y que sugiere una suerte de encuentro entre la tradición europeo-continental tan apegada a los códigos normativos y la tradición norteamericana que tempranamente estructuró su ideal de democracia sobre la base de los derechos individuales inalienables ${ }^{4}$.

Es en este contexto que las decisiones de los tribunales o cortes constitucionales se han convertido en una pieza fundamental en el discurso jurídico contemporáneo y en un poderoso instrumento para la defensa, tanto del modelo de democracia constitucional como de los derechos fundamentales contenidos en las constituciones. La razón de esto puede encontrarse en el consenso que ha alcanzado en la vida de las democracias más consolidadas la idea del control del poder a través del juicio de constitucionalidad, o la propia defensa de los derechos fundamentales a través de la jurisdicción constitucional, que muestran al juez constitucional como un "soberano" bastante querido por los "súbditos" del Estado constitucional.

Desde otro lugar, Cappelletti ha presentado a la jurisdicción constitucional como la "más importante y más prometedora de las respuestas que un número creciente de naciones ha intentado dar al problema de la opresión gubernamental" 5 . El juez constitucional es, desde esta perspectiva, un garante frente al "enemigo" histórico de las libertades, esto es, el Estado mismo. En este sentido, se ha sostenido que la creciente presencia de los tribunales constitucionales, que constituyen una suerte de timonel en la marcha de la justicia constitucional, "ha desafiado al clásico princi-

nista del Estado Social y Democrático de Derecho. Se trata, en palabras de Luis Prieto, de la transformación que va operando en los sistemas jurídicos contemporáneos como consecuencia de asumir "una Constitución transformadora que pretende condicionar de modo importante las decisiones de la mayoría, pero cuyo protagonismo fundamental no corresponde al legislador, sino a los jueces". Prieto SANChís, Luis (2002). Derechos fundamentales, neoconstitucionalismo y ponderación judicial. Lima: Palestra.

2 Häberle, Peter (2001). "La jurisdicción constitucional institucionalizada en el Estado Constitucional". Traducción de Joaquín Brague Camazano. Anuario Iberoamericano de Justicia Constitucional, No 5, Madrid. Recientemente ha sido incluido en el volumen del autor publicado en Perú bajo el título de: Nueve ensayos constitucionales y una lección Jubilar (2004) Lima: Palestra, p. 128.

3 Shapiro, M. (2008). "Revisión Judicial en democracias desarrolladas". En: Tribunales Constitucionales y democracia. México: Suprema Corte de Justicia de la Nación, p. 242.

Hamilton, Alexander (2000). "Paper No LXXVIII". El Federalista, México: FCE.

Cappelletti, Mauricio (1986). “¿Renegar de Montesquieu? La expansión y la legitimidad de la "justicia constitucional". Revista Española de Derecho Constitucional, No 17 , p. 13. 
pio de división de poderes" 6 , constituyéndose en la práctica en una suerte de árbitro inseparable de dicha "división".

Ingresando en el ámbito propio de sus competencias, desde España, el destacado iuspublicista Eduardo García de Enterría, luego de valorar a la judicial review norteamericana como "la clave de bóveda" para el desarrollo histórico de la justicia constitucional también en Europa, acuñará la famosa expresión, al considerar al Tribunal Constitucional como "un verdadero comisionado del poder constituyente para el sostenimiento de su obra, la Constitución, y para que mantenga a todos los poderes constitucionales en su calidad estricta de poderes constituidos" (cursiva agregada) ${ }^{7}$. No sería pues un celoso restaurador o guardián de las grafías o textos históricos ${ }^{8}$, sino un delegado actual para defender su obra interpretándola en cada momento histórico y contextualizándola conforme a los requerimientos de cada época.

Aun cuando esta tesis no ha merecido mayor polémica en su país de origen, quizá por el prestigio y ascendencia de su mentor, no hay que olvidar, sin embargo, que se trata de un "punto de vista" respecto del nada pacífico espacio y competencias que corresponde a un Tribunal Constitucional en un contexto en el que, no se puede seguir subestimado "la envergadura del problema" ${ }^{\prime}$ de su legitimidad. Un problema que enfrenta

Landa Arroyo, César (2007). Tribunal Constitucional y Estado Democrático. Tercera edición, Lima: Palestra, p. 74.

7 García de EnTERría, Eduardo (1981). "La posición jurídica del Tribunal Constitucional en el sistema español: posibilidades y perspectivas". Revista Española de Derecho Constitucional, vol. 1. Núm. 1. Enero-abril, p. 98. También en García de EnTerría, Eduardo (1983). La Constitución como norma y el Tribunal Constitucional, 3a edición, Madrid: Civitas, p. 198 .

8 Aunque esta sea la tesis sustancial de lo que se ha dado en llamar el strict constructionists y del originalismo norteamericanos. El originalismo ha tenido gran desarrollo, sobre todo en el Derecho Constitucional norteamericano y ha respondido al prestigio que ha adquirido, en sus más de 200 ańos, la Constitución de los Estados Unidos. Sobre el originalismo y su actual desarrollo, ver Alonso García, Enrique (1984). La interpretación de la Constitución. Madrid: Centro de Estudios Políticos y Constitucionales. Una versión de textualismo lingüístico, aunque con matices propios del contexto europeo, puede verse en el caso español en, García Amado, Juan A. (2003). "Sobre la interpretación Constitucional". Ensayos de Filosofia jurídica, Bogotá: Temis, pp. 67 y ss.

9 En este sentido Juan Carlos Bayón da cuenta de la poca relevancia que solía darse en Europa, hasta hace poco, al problema "contra mayoritario" que representa, también aquí, la justicia constitucional. Una situación que solía darse por superada atendiendo a que, en el caso espańol al menos, "está expresamente establecida en el texto constitucional, aprobado democráticamente". BAYON, Juan Carlos (2004). "Democracia y derechos: problemas de fundamentación del constitucionalismo". En AA. VV.: Constitución y Derechos Fundamentales. Madrid: CEPC, p. 74. También García de Enterría da por resuelto el problema, al sostener que "la cuestión (el de la legitimidad de la justicia constitucional) ha sido ya juzgada por el Tribunal de la Historia, ante el cual la justicia constitucional no solo ha sido absuelta de tan graves cargos, sino que se ha afianzado definitivamente como una técnica quintaesenciada de gobierno humano". GARCía DE ENTERRía (1981) 79. Las permanentes disputas y conflictos que se desatan tras su actuación, sobre todo en contextos donde, tardíamente, vie- 
la concepción misma de la democracia constitucional y las relaciones y "desacuerdos" que se producen entre la política y los derechos, así como la forma en que los mismos deben ser resueltos ${ }^{10}$.

\section{(1.1) El Tribunal Constitucional como “órgano oficial" De INTERPRETACIÓN}

Sea como fuere, al margen de este debate que tiene dimensiones no solo jurídicas sino fundamentalmente políticas y hasta sociológicas, los tribunales constitucionales suelen ser identificados en las democracias contemporáneas como "intérpretes supremos" o, mejor aún, como órganos "oficiales" de asignación de significados a los textos constitucionales ${ }^{11}$. Una suerte de traductor oficial de las grafías del constituyente, y si se entiende por "grafía" -como lo hace la Real Academia Española- el "Modo de escribir o representar los sonidos", el Tribunal Constitucional bien puede ser representado simbólicamente como la orquesta oficial encargada de interpretar los "sonidos constitucionales" adecuando su ritmo y compás a cada tiempo y época en que se ejecute.

El que sea la "orquesta oficial" no quita la posibilidad, desde luego, que también la melodía constitucional pueda ser interpretada y ejecutada por otras orquestas o incluso por "solistas aficionados" 12 . La oficialidad no quiere decir aquí estatalidad de la interpretación, ni mucho menos verticalidad para imponer alguna "verdad oficial". La sociedad plural del Estado constitucional no podría admitir intérpretes oficiales en tal sentido. En cualquier caso, el rótulo de orquesta oficial solo quiere poner de manifiesto la calidad de sonido auténtico de la melodía que debe ser interpretada de manera autorizada por dicha "orquesta oficial". El Tribunal actúa así, en más de una ocasión, como una especie de "retocador" de

ne implementándose, son, sin embargo, suficiente indicio de que no estamos ante un asunto cerrado por el "tribunal de la historia".

10 Otro "punto de vista" es sin duda el que propone Waldron, Jeremy (2005). Derecho y Desacuerdos. Traducción de J. L. Martí y Â. Quiroga. Madrid: Marcial Pons, p. 264. Un intento de armonizar democracia representativa y poder de control de los jueces puede verse en: Ely, John (1980). Democracy and distrust. A theory of judicial review. Harvard University Press, 1980. Cito de la versión castellana, Democracia y desconfianza. Una teoría del control Constitucional (1997). Bogotá: Siglo del Hombre Editores, Universidad de los Andes, 1997.

11 Gracias a la redacción de la revista, tengo acceso al texto de la Constitución de Ucrania que curiosamente encomienda al Tribunal Constitucional "la interpretación oficial de la Constitución de Ucrania y de las leyes de Ucrania" (artículo 150). Una apreciación crítica a este precepto puede verse en: STITH, Richard (2005). "Imperio del Derecho versus Imperio de los Jueces: un alegato por el pluralismo jurídico". Revista de Derecho Universidad Católica del Norte, ańo 12, No 1, pp. 157-182.

12 Intérpretes autorizados y necesarios de la Constitución son desde luego el Parlamento, el Poder Ejecutivo, los órganos constitucionales autónomos, etc. 
múltiples interpretaciones, todas posibles desde el atril de la Constitución, institucionalizando las versiones de otros intérpretes que no tienen la posibilidad de hacer valer sus versiones si no fuera por la recepción que pueda hacer de estas el Tribunal Constitucional. En este sentido, también actúa "convirtiendo" en oficial otras versiones posibles en la recreación acústica de la Constitución ${ }^{13}$.

Tener la responsabilidad de una interpretación autorizada de la partitura constitucional le ha merecido al Tribunal un prestigio indiscutible, sobre todo si analizamos sus hazañas en contextos de estabilidad democrática ${ }^{14}$. Pese a este prestigio que está precedido, como ya dijimos, de aquel que ha adquirido en el contexto de las democracias actuales, el propio modelo del constitucionalismo como modelo de organización que maximiza los controles ${ }^{15}$ viene suscitando constantes disputas con otros actores de la vida democrática, como son el Parlamento, el propio Poder Judicial, los organismos autónomos ${ }^{16}$ cuando no el propio gobierno o incluso determinados actores sociales, como las ONG o determinados sectores organizados de la sociedad. En este contexto, el argumento más recurrente ha sido, desde luego, el acusar al Tribunal de carencia de legitimidad democrática para ejercer el control del Parlamento ${ }^{17} \mathrm{o}$, cuando se trata del Poder Judicial, se suele recurrir al principio de independencia judicial, dejando entrever que la anulación de una sentencia firme por parte

Se puede hablar en este sentido del "derecho de acceso a la interpretación constitucional" a través de los procesos constitucionales que es la vía a través de la cual la sociedad plural participa de este "proceso público", como lo ha llamado Häberle.

Expresiva de estas hazańas es la siguiente frase de Alexy que alude a la obra del Tribunal Federal alemán: "Hoy en día no se puede colegir lo que representan los derechos fundamentales a partir del sucinto texto de la Ley Fundamental, sino solo a partir de los 94 volúmenes de Sentencias del Tribunal Constitucional Federal que hasta la fecha ha registrado en total su benéfica actividad desde el siete de septiembre de 1951. Los derechos fundamentales son lo que son sobre todo a través de la interpretación". Alexy, Robert (2003). "Los derechos fundamentales en el Estado constitucional democrático". Traducción de Alfonso García Figueroa. En Carbonell, Miguel (ed.): Neoconstitucionalismo(s). Madrid: Trotra.

Una caracterización del constitucionalismo en sus rasgos fundamentales puede verse en: Prieto Sanchís, Luis (2004) "El constitucionalismo de los derechos". Revista Española de Derecho Constitucional, No 71, Madrid.

16 Especialmente relevante y significativa de esto es en el contexto peruano la reticencia pública frente a las sentencias del TC por parte del Jurado Nacional de Elecciones o del Consejo Nacional de la Magistratura. En ambos casos el TC ha establecido que tales organismos no están exentos de control por parte del Tribunal en su actuación, cuando violen algún derecho fundamental. Sobre las reacciones del propio Parlamento frente la TC, puede verse el proyecto de reforma constitucional que intenta limitar las potestades interpretativas de este organismo. Ver al respecto, AA. VV. (2006), Tribunal Constitucional y control de poderes. Lima: Centro de Estudios Constitucionales.

Sobre el carácter contra mayoritario de la justicia constitucional, las referencias son extensas. Cito por todas la reciente argumentación contra esta tesis que ha propuesto BAYON, Juan Carlos (2004). "Democracia y derechos. Problemas de fundamentación del constitucionalismo". En AA. VV. Constitución y Derechos Fundamentales. Madrid: Presidencia de Gobierno, Secretaría General Técnica, pp. 67-138. 
del Tribunal supone, en muchos casos, la afectación no solo de la cosa juzgada, sino también de la propia independencia y autonomía del Poder Judicial ${ }^{18}$. Pero quizá la acusación que más debe preocupar a un Tribunal que decide conflictos como tercero imparcial sea el que se cuestione precisamente su falta de independencia e imparcialidad en determinadas causas, puesto que en el mantenimiento de estos valores radica la propia legitimidad del Tribunal ${ }^{19}$.

\section{(1.2) EL CONTROL CONSTITUCIONAL COMO COLABORACIÓN}

Frente a la acusación de actuar en "terreno ajeno", o peor aún, en sentido contra mayoritario y sin la legitimidad necesaria, sobre todo cuando se trata del control de la legislación, Lawrence $\operatorname{Sager}^{20}$ ha sugerido la idea de la colaboración como un modelo posible entre los esquemas teóricos que tratan de describir la práctica de la judicial rewiev. La idea de la colaboración resulta del hecho real de "la generalidad con la que se expresan la mayoría de las cláusulas que garantizan la libertad", lo que requiere para su concreción de "interpretaciones elaboradas", puesto que no se tratan (las cláusulas constitucionales) de "instrucciones para la resolución de casos específicos", sino más bien de "ideales normativos", en los que los "juicios" de los tribunales resultan indispensables. De este modo, "la tarea de interpretar la Constitución requiere la colaboración entre las generaciones constituyentes que fijaron el texto de este documento y quienes tienen la función de aplicar los preceptos textuales a casos concretos que se plantean en nuestra comunidad política" 21 .

La idea de la colaboración se presenta así, como una tesis sugestiva que puede ahuyentar cualquier prejuicio que ve en la presencia de los tribunales una suerte de "fiscalizador" antidemocrático. Por lo demás, en la práctica, es claro que la presencia del Tribunal contribuye también al propio fortalecimiento tanto del Parlamento como del Poder Judicial, en la medida en que en la gran mayoría de casos el Tribunal confirma la constitucionalidad no solo de la ley, sino también de la actuación del Poder Judicial en ejercicio de la potestad jurisdiccional. Este dato resulta

18 En el contexto peruano, expresivo de este tipo de problemas es la sentencia del Tribunal Constitucional dictada en el Exp. No 006-2006-CC/TC (Poder Ejecutivo v. Poder Judicial). Un análisis crítico de esta decisión puede verse en García Belaunde, Domingo (2007). "¿Guerra de las Cortes? A propósito del proceso competencial entre el Poder Ejecutivo y el Poder Judicial". Cuadernos de análisis y critica a la jurisprudencia constitucional $\mathrm{N}^{\circ}$ 4, Lima: Palestra Editores.

19 Zagrebelsky, Gustavo (2008). Principios y votos. El Tribunal Constitucional y la política. Traducción de Manuel Martínez Neira. Madrid: Trotta.

20 SAGER, L. G. (2004). Juez y Democracia. Una teoría de la práctica constitucional norteamericana. Traducción de Víctor Ferreres Comella. Madrid: Marcial Pons, p. 44. 
relevante en democracias con déficit de legitimidad social y donde existe también fragilidad de las instituciones. En estos contextos, el Tribunal Constitucional bien puede ser visto también como un auténtico moderador de las luchas o conflictos de intereses y un pacificador de las tensiones que se producen entre el Derecho y los poderes fácticos ${ }^{22}$. De este modo, parece más razonable comprender el accionar del Tribunal como un colaborador en el desarrollo de las instituciones de la democracia y, llegado el caso, como un comprometido "nivelador" de las serias asimetrías existentes en una sociedad fragmentada como la nuestra, que en muchos casos compromete la propia dignidad humana, como es el caso de la extrema pobreza $^{23}$.

Con relación a las "tensiones" con el Poder Judicial, esto acontece en nuestro medio, en el marco de un claro "despertar" del juez ordinario como juez del Estado constitucional, que encuentra en el Tribunal Constitucional una suerte de "superjuez", capaz no solo de actuar como instancia definitiva en los procesos constitucionales, sino que, además, se presenta como un poder de corrección sustancial del proceder de la justicia ordinaria, invalidando sus decisiones cuando estas, a criterio del Tribunal, invaden zonas vedadas, como son los derechos fundamentales ${ }^{24}$. En el caso peruano, tal actuación se desarrolla además en un esquema bastante imperfecto de articulación entre Poder Judicial y Tribunal Constitucional ${ }^{25}$, lo que permite, en muchos casos, un avance en las potestades del máximo intérprete constitucional, apoyado en su propia doctrina jurisprudencial ${ }^{26}$, que tiene, en los últimos ańos, un importante arsenal

Una lectura en esta dirección puede verse en Grández Castro, Pedro (2006). "Tribunal Constitucional y transición democrática. Un ensayo de interpretación de su actuación”. Gaceta Constitucional No 4, Lima: Tribunal Constitucional. Disponible en: http://www.tc.gob. pe/gaceta

24 Esto ocurre por ejemplo con el control de decisiones judiciales penales, en las que el Tribunal peruano no ha dudado en actuar, en más de una ocasión, ya no solo como juez excepcional, sino como verdadera instancia de corrección, incluso controlando el solo avocamiento en un proceso penal, al admitir por ejemplo el control del auto de apertura de un proceso penal. Véase la reciente sentencia en el caso, John McCarter, Contra la Primera Sala Penal para procesos con reos libres de la Corte de Lima. Tribunal Constitucional del Perú. Exp. No 4989-2006-PHC/TC.

Sobre el desarrollo de estas relaciones en los últimos ańos, Eguiguren Praeli, Francisco (2002). "Relaciones entre el Poder Judicial y el Tribunal Constitucional en el Perú", en él mismo: Estudios Constitucionales. Lima: ARA, pp. 341 y ss.

Especial lugar ocupa en esta dirección la llamada autonomía procesal del Tribunal, recogida en tales términos de la jurisprudencia alemana y que ha servido de argumento central a muchas de las "intervenciones" por parte del TC peruano, en el seno de las decisiones del juez ordinario. Sobre la autonomía procesal y su recepción en la jurisprudencia del TriBUNAL Constitucional del Perú. STC No 0025-2005-PI/TC y 0026-2005-PI/TC (Auto de admisión). Si bien se trataba en esta ocasión de una demanda de inconstitucionalidad, lo cierto es que la doctrina de la autonomía procesal del TC y la concepción del Derecho Procesal Constitucional, como "(...) un ordenamiento complejo de naturaleza adjetiva", orientado 
teórico a partir de una práctica de recepción que ha sido manifiesta en los últimos años ${ }^{27}$.

Salidos de los cauces y disputas institucionales, el Tribunal Constitucional se enfrenta a otras tantas amenazas respecto de su legitimidad. Esta vez es su actuación en las decisiones difíciles para la sociedad misma. Las cuestiones sobre la moral pública deducidos desde la Constitución como auténticos problemas jurídicos llegan de modo inevitable al Tribunal y someten a este a nuevos desafíos ${ }^{28}$. Las características de una sociedad pluralista, con múltiples credos y aspiraciones que conviven en el Estado Democrático, hace inevitable que las soluciones no puedan satisfacer a todos. Las muestras abundan, desde el aborto y el Derecho penal, hasta la libertad religiosa y la tolerancia; sin dejar de mencionar el clásico conflicto entre libertad de expresión e información con los derechos al honor e intimidad ${ }^{29}$.

Este es, más o menos, el escenario en que transita actualmente la justicia constitucional, no solo en Europa, sino también en los países donde se ha venido desarrollando en los últimos años el Estado constitucional, como es el caso peruano. En cualquiera de los escenarios, el Tribunal Constitucional es, no obstante, juez vinculado a la Constitución que debe dar cuenta pública de sus decisiones y en el que sin duda la argumentación juega un rol relevante.

\section{(1.3) LA ARGUMENTACIÓN COMO ESTRATEGIA DE LEGITIMACIÓN Y EL TRIBUNAL COMO INSTITUCIÓN REPUBLICANA}

Frente al panorama descrito, la justificación (argumentación) se presenta como una poderosa herramienta de autolegitimación, no solo para el TC, sino para el poder jurisdiccional en general, entendido como poder

a los fines "del ordenamiento sustantivo a cuya concretización sirve la Constitución"; viene generando espacios de actuación, especialmente importantes a la hora de controlar las propias decisiones de los jueces ordinarios a través, sobre todo, del proceso de amparo contra decisiones judiciales. Landa Arroyo, César (2006). "La autonomía procesal del Tribunal Constitucional". Justicia Constitucional, ańo II No 4, Lima.

27 Pegoraro, L. "La utilización del derecho comparado por parte de las Cortes Constitucionales: un análisis comparado. Disponible en: http://www.iustel.com/v2/revistas/detalle_revista.asp?id... [fecha de visita 10 de septiembre de 2009].

28 En el caso peruano, este extremo tampoco ha estado ausente. Solo como muestra véase el caso sobre la píldora del día siguiente, resuelto vía un proceso de cumplimiento en el Exp. No 7435-2006-PC/TC. Esta decisión ha sido dejada de lado en una polémica decisión del Tribunal por mayoría, que dispuso que el gobierno peruano se abstenga de repartir en forma gratuita el AOE a través de los centros de atención del Ministerio de Salud. Tribunat. Constitucional del Perú. STC 2005-2009-AA/TC.

29) Sobre estos conflictos en el caso peruano Eguiguren Praeli, Francisco (2004). La libertad de expresión e información y el derecho a la intimidad personal: su desarrollo actual y sus conflictos. Lima: Palestra Editores. Más recientemente, Mendoza Escalante, Mijail (2007). Conflictos entre derechos fundamentales: expresión, información y honor. Lima: Palestra Editores. 
compartido entre jurisdicción ordinaria y jurisdicción constitucional. Frente a las "fuerzas" de la política, de los grupos de presión, de las "mayorías", de los medios de comunicación y sus "juicios paralelos", "los jueces solo pueden utilizar la fuerza de las razones jurídicas" 30 . Justificando cada una de sus decisiones, el juez logra conectar su potestad jurisdiccional con la república que es, en la sutil distinción de Zagrebelsky el genus de la democracia que es la especie. De este modo, frente a las desviaciones o "degeneraciones" de la especie, la justicia constitucional que protege al género que es la república, reivindicándola, puede incluso limitar "(...) la democracia porque sirve para preservar el carácter de especificación de la república (...)" en tal sentido: "la justicia constitucional es una función republicana" 31 .

Comprender la actuación de la justicia constitucional desde la perspectiva de la república y no de la democracia no supone, sin embargo, renunciar a la necesidad de presentar argumentos a favor de su legitimidad. La justificación es aquí el arma inofensiva pero irrenunciable del carácter republicano de la función jurisdiccional del juez constitucional. La motivación de las decisiones del juez constitucional se presenta en este punto, no solo como legitimación de su propia existencia, sino también como punto de contención frente a las críticas que suelen hacerse a la forma en que desarrolla su accionar frente a los demás poderes, más conectados con la legitimidad que proyecta la democracia.

Se trata de comprender la argumentación constitucional en su doble función: como actividad orientada al proceso en concreto, pero también como proceso público de decisión en el que el órgano constitucional logra legitimarse en sus funciones. No es solo "técnica" de la subsunción para la corrección en el razonamiento deductivo, sino discurso abierto en busca de adhesiones ${ }^{32}$. Esto supone, desde luego, asumir una cierta concepción de la Constitución y sus contenidos y también de las posibilidades de actuación de un Tribunal Constitucional en un determinado contexto o realidad.

Una teoría de la argumentación constitucional debe asumir, de este modo, que ya no se trata solo de conectar los textos de la Constitución con determinadas teorías jurídicas de interpretación de textos legales, porque la Constitución no puede ser comprendida como un texto legal más, sino más bien, como un pacto social que intenta la cohesión de una sociedad plural que, pese a todo, confía en las soluciones jurídicas de sus problemas. De manera que "la interpretación constitucional en sociedades desintegradas debe pasar por incorporar la realidad en la norma e

ZAGREBELSKY (2008) 100.

ZAGREBELSKY (2008) 102.

VieHWeg, Theodor. (1964). Tópica y jurisprudencia. Traducción de Luis Díez-Picazo. Madrid: Taurus. 
interpretar a esta a través de las instituciones"33. Habría que postular entonces la necesidad de migrar el discurso de la interpretación jurídica a la argumentación $^{34}$ para abrir de este modo el razonamiento técnico jurídico al razonamiento moral y social más amplio, al discurso práctico general, como lo ha propuesto Alexy ${ }^{35}$, asumiendo, al mismo tiempo y sin ambages, como diría Jestaedt ("para evitar confusiones"), que no asistimos aquí a labores propias del "conocimiento" de normas del Derecho mediante actos de "interpretación", sino que se trata de actos "abiertamente de producción de derecho" 36 .

En una tarea de tal envergadura, la interpretación constitucional no puede limitarse a una actividad de técnica jurídica ${ }^{37}$, pues se trata en el fondo de asumir compromisos y convicciones sobre valores, derechos y preferencias a partir de un texto que, en muchos casos, resulta demasiado parco para el jurista acostumbrado a las subsunciones o, precisamente, debido a esas "ambigüedades gloriosas" 38 de que están plagados los textos constitucionales que recogen derechos fundamentales. Más aún, la multiplicidad de métodos, antes que caminos "objetivos" para encontrar respuestas correctas y únicas desde la Constitución, nos hablan de diversos modos de entender el Derecho o la Constitución a partir de ciertas con-

LANdA Arroyo (2007) 573.

En este sentido se pronuncia Matthias Jestaedt en un trabajo que resume los cambios que se van produciendo en la ciencia del Derecho Público europeo sugiriendo un "relevo" de la interpretación por la concretización y la argumentación. Esto porque las actividades de concretización no son actividades de "conocimiento" de algo preexistente (lex ante casum), sino más bien producción misma de normas. Jestaedt, Matthias (2008). "El Derecho Público: una ciencia". En Eduardo Montealegre (coord.): La ponderación en el Derecho. Bogotá: Universidad Externado de Colombia, pp. 11 y ss.

35 En este sentido Alexy ha planteado la necesidad de conectar el razonamiento jurídico con el razonamiento práctico: "La necesidad de razonamiento jurídico, como algo más que la mera subsunción y, en cuanto tal, más que la mera ejecución de lo autoritativo, surge de la frecuentemente mencionada textura abierta del material autoritativo [HART (1994) 126 y ss.]. El razonamiento en defecto de material autoritativo puede, por definición, no estar determinado únicamente por lo que es autoritativo. Este razonamiento puede resultar libre hasta un cierto grado". Alexy, Robert (1999). "La tesis del caso especial". Isegoría No 19, p. 24.

Jestaedt (2008) 38.

Aun cuando incluso en esta tarea, hasta hace poco, se denunciaba cierta ausencia de trabajos de investigación en el campo constitucional. Así por ejemplo el profesor Pérez Luño en la década del 80 del siglo pasado daba cuenta con "cierta perplejidad", la "escasa atención que ha merecido en la teoría jurídica el tema de la interpretación constitucional". Pérez Luño, Antonio (1984). Derechos humanos, Estado de Derecho y Constitución. Madrid: Tecnos. Por esos mismos años, Francisco Rubio Llorente, con modestia confesaba enfrentarse a una "nova terra" al referirse a la interpretación constitucional y luego tranquilizándose un poco escribía: "Una consideración bien simple viene a tranquilizarme: la de que este antiguo desinterés y reciente apasionamiento por el problema de la interpretación no es una veleidad personal, sino por así decirlo, una actitud colectiva", Prólogo a Alonso García, E. (1984) La interpretación de la Constitución. Madrid: Centro de Estudios Políticos y Constitucioales. La frase se le atribuye al juez norteamericano Hufstedler. García de Enterría (1981) 123, la fuente puede verse en el pie de página No 243. "No es con ironía como yo califico los términos del Bill of Rights de 'ambigüedades gloriosas". 
cepciones de la vida práctica, o a partir de ciertas ideologías de la propia interpretación ${ }^{39}$.

Parece así indispensable el abordar el problema en su dimensión integral, esto es, ver la actuación de los tribunales constitucionales como órganos de asignación de derechos y de creación de normas constitucionales $^{40}$ a partir de su actuación jurisdiccional, esto es, a partir de la argumentación que desarrollan de cara a los casos concretos. Ello supone analizar la estructura misma del razonamiento del juez constitucional y asumir de entrada el rol que juega en esta tarea los esquemas mentales o ideologías como "precomprensiones" tanto de la Constitución como de la realidad a la que se proyecta.

Que los jueces constitucionales justifiquen o argumenten sus decisiones parece una obviedad; es más, en la práctica, es posible encontrar que las sentencias constitucionales son bastante más extensas y consistentes en argumentos respecto de las que expide el Poder Judicial. Lo cual, desde luego, tampoco quiere decir que estén bien fundamentadas y, menos aún, que las respuestas dadas a los casos planteados sean, desde un punto de vista jurídico, siempre las correctas. "Una suma de argumentos no asegura la solución correcta", anota Garrido Falla ${ }^{41}$ desde su experiencia personal como magistrado del TC español.

¿Cómo debe pues afrontarse el problema de la justificación racional de la decisión jurisdiccional y, en concreto, el de la justificación de la sentencia constitucional? ¿Es posible dar respuestas correctas desde la Constitución? ¿Cuáles son los modelos teóricos y como actúa en la práctica un Tribunal Constitucional? El punto de partida para responder estas cuestiones debe ubicarse en los recompromisos o preconcepciones que constituyen el primer parámetro en el discurso argumentativo de los tribunales.

\section{2) IDEOLOGÍAS Y ARGUMENTACIÓN}

Todas las interrogantes planteadas supra no pueden ser abordadas en esta ocasión. Aquíí ${ }^{42}$, nos limitamos a indagar sobre los modelos o esquemas ideológicos ${ }^{43}$, otrora explorados con ocasión de analizar las actitudes

Guastini, Ricardo, (2007). Teoria e ideologia de la interpretación constitucional, traducción de Miguel Carbonell y Pedro Salazar, Madrid: Trotta.

40

Spadaro, Antonio (2007). "Las motivaciones de las sentencias de la Corte como 'técnica' de creación de normas constitucionales". Palestra del Tribunal Constitucional. Año 2, No 12.

Garrido Falla, F. (2002). "La elaboración de las sentencias del Tribunal Constitucional: una experiencia personal". Teoría y realidad constitucional, UNED, No 10-11, p. 143.

El presente trabajo forma parte de uno de mayor extensión sobre la argumentación constitucional y sus problemas que se encuentra en preparación.

Conforme escribe Guastini, "en la historia del pensamiento jurídico moderno se cuentan -podemos decir que desde siempre- tres oposiciones doctrinales principales: (i) la oposición 
del juez frente a la ley ${ }^{4}$, como puntos de partida para una indagación sobre la argumentación constitucional y sus problemas. Las actitudes del juez, obviamente, deben también ser analizadas a partir de los modelos o concepciones de Constitución, pues es claro que no da lo mismo interpretar o argumentar a partir de una Constitución entendida como norma política o procedimental, que hacerlo desde una Constitución entendida como norma material o con contenidos que condicionan el propio proceso político ${ }^{45}$.

En lo que sigue, sin embargo, quisiera referirme a las actitudes más saltantes con relación a la interpretación de la Constitución y que creo expresan pre-compresiones ${ }^{46}$ que condicionan de manera relevante el trabajo judicial y la respuesta que suelen dar los tribunales constitucionales en la mayoría de casos.

\section{(2.1) El "JUez VinCUlado" AL TEXTO DE LA CONSTITUCión: El CONTROL SEMÁNTICO DE LA CONSTITUCIÓN}

El primero de los esquemas ideológicos frente a la Constitución en Europa continental tiene su antecedente en la actitud de los exegetas frente al Código de Napoleón. Esto es, una actitud de dependencia y de compromiso frente a la obra del legislador racional y expresión del poder legítimo de la burguesía en el poder. Se trata de ver en el juez un órgano de ejecución de los actos legislativos. De este modo, se pretende separar conceptualmente los actos de creación (política) de la ley, con los actos de aplicación (técnico-judicial) a cargo de los jueces a quienes se les delega un "poder nulo" o de simple subsunción.

En la medida que el juez del Antiguo Régimen era un juez dispuesto al soberano, pero también a su propia voluntad, la idea de los revolucionarios franceses era limitar el razonamiento judicial a la simple aplicación de la ley. De ahí que Montesquieu haya escrito que: "Si las sentencias fueran una opinión particular del juez se viviría en la sociedad sin saber con exactitud los compromisos contraídos con ella; sin embargo, puesto que el poder judicial tiene que renunciar a su opinión particular en aras

entre una ideología "estática" y una ideología "dinámica"; (ii)la oposición entre una ideología "universalista" y una doctrina "particularista"; (iii) la oposición entre una actitud de judicial restraint y una actitud de judicial activism”. GUASTINI (2007) 59.

44 Prieto SAnchís, Luis (1987). Ideología e interpretación juridica, Madrid: Tecnos.

45 Sobre estos modelos véase: Aguiló Regla, Josep (2004). La Constitución del Estado Constitucional. Lima-Bogotá: Palestra, Temis, especialmente el Cap. II. También ComanduccI, Paolo (2005). "Modelos e interpretación de la Constitución". En Eduardo Ferrer MacGregor (coordinador): Interpretación Constitucional, t. I, México: Porrúa, pp. 469 y ss.

46 Utilizo el término pre-comprensión en el sentido de Gadamer, Hans-Georg (1977). Verdady método. Salamanca: Ed. Sígueme. 
de la generalidad de la ley, ha de aspirar por tanto a ser un poder nulo" 47 . Desde esta perspectiva, es de algún modo, el cambio de la voluntad particular del juez por la razón de la ley la que opera con el advenimiento del nuevo régimen tras la revolución burguesa.

Si trasladamos este esquema mental a la aplicación de la Constitución y vemos en ella una ley más, es fácil suponer el modelo de argumentación y de judicatura constitucional resultante. Aunque existen diversos matices al interior de un entendimiento como el presentado aquí, podríamos afirmar, de manera general, que el textualismo ${ }^{48}$ es una buena expresión de este modelo ideológico. Según esta concepción, la Constitución debe ser interpretada atendiendo a lo que los constituyentes quisieron expresar al escribir determinado texto, de modo que la argumentación constitucional tiene como objeto el conocimiento o averiguación respecto de las grafías y de los significados tal como se entendieron en el momento en que fueron escritos.

En este sentido, García Amado expresará que "para la concepción lingüística o textual el juez, y el juez constitucional, es guardián de las palabras, vela por su significado haciendo que se respeten cuando son ciertas y determinadas y las precisa y concreta en lo que tengan de indeterminadas", comportándose como "juez hermano (por cuanto hijo del mismo lenguaje de todos o sometido a él como todos)" 49 . Más recientemente García Amado ha insistido en una suerte de nuevo "noble sueño" al sostener que: "No es mera perogrullada si afirmamos que la Constitución dice lo que dice y solo dice lo que dice".

Este modo de entender el proceso de interpretación constitucional como un acto de conocimiento o indagación en los textos se deriva inmediatamente un modelo de judicatura constitucional cuya actividad central es, como lo precisa el propio García Amado, una actividad de control "negativo puro, consistente en inaplicar y declarar inconstitucional, en su caso, las normas legales que patentemente vulneran la semántica de los enunciados constitucionales" (cursiva agregada) ${ }^{50}$. En esta línea, la actividad de los tribunales constitucionales bien podría estar encomendada no a juristas con reconocida trayectoria profesional, como ocurre en la mayoría de los países, sino a filólogos o especialistas en descubrimiento de los significados "originarios" de textos arcaicos.

En esta misma dirección, aunque con matices propios de su tradición, encontramos al originalismo norteamericano sustentado, como es

Montesquieu (2007). El espiritu de las leyes. Lib. XI, Cap. 6, Madrid: Dykinson.

García Amado, Juan A. (2004). "La interpretación constitucional". Revista Juridica de Castilla y León, № 2, pp. 35 y ss.

García Amado (2004) 61.

García Amado, Juan Antonio (2007). "Derechos y pretextos. Elementos de crítica del neoconstitucionalismo". En: Carbonell, Miguel (2007) 239. 
conocido, en la legitimidad histórica y social con que cuenta en dicho país los framers o padres fundadores ${ }^{51}$. No obstante, se trata, también aquí, de reafirmar la vinculación a los autores del texto constitucional y, desde esta concepción, reducir el papel del juez constitucional a un ser angustiado por encontrar el sentido de las frases contextualizándolas, además, en el momento en que fueron escritas.

El juez de la Corte Suprema de los Estados Unidos, Antonin Scalia, es sin duda el exponente más visible del originalismo de nuestros días. Para el Justice Scalia, la interpretación de la Constitución constituye una actividad orientada a “( $\ldots)$ tratar de entender qué es lo que quiere decir, qué entendió la sociedad y qué significaba cuando fue adoptada. No creo que ello haya cambiado desde entonces". Frente a la tesis de una concepción evolutiva en la interpretación constitucional, que permita incorporar los cambios a través de las decisiones judiciales, el Justice Scalia reacciona de manera enérgica: “QQué los hace pensar que el progreso humano es un plano inclinado que, todos los días y de todas las maneras posibles, nos hace mejores y mejores? A mí me parece que el propósito del Bill of Rights fue prevenir el cambio, no alentarlo y escribir ese propósito en la propia Constitución" 52 .

Textualismo y originalismo, aun con sus múltiples variantes de contexto, confluyen, sin embargo, en sus fundamentos y modos de abordar determinados problemas jurídicos que tienen como punto de discordia la asignación de significados a un texto constitucional. Aun cuando no es posible (y con frecuencia ahí radica el problema) distinguir el significado literal de un texto de la intención de su autor, el originalismo, a diferencia de como lo haría un textualista contemporáneo, pretende reconstruir el significado de un texto a partir de la intención del autor del mismo.

De este modo, cabría hacer alguna distinción entre textualismo y originalismo, en la medida que, al menos para un sector, desde el textualismo lingüístico, es posible separar el significado del texto, en sentido objetivo, de las intenciones de su autor (sentido subjetivo). En el primer caso se trata de construir los significados, al margen de las intenciones del autor, incluso acudiendo a convenciones linguísticas o técnico-jurídicas, mientras que en el textualismo de tipo subjetivo, lo determinante es el significado original, tal como lo entendía su autor o autores. Para ser justos, esta sería la postura más compatible con el originalismo semántico,

Puede resultar ilustrativo hacer notar que al menos una de las posibles traducciones de la palabra en inglés "framer" sea el de carpintero que construye cuadros o que enmarca una obra de arte (poner el marco a una obra). Con lo cual esta concepción también vendría a reivindicar una cierta concepción de Constitución entendida como "marco" establecido o fijado por los "fundadores" sobre la base del que la legislación tendría cierta libertad "discrecional" para elaborar la legislación.

52 Traducción libre del debate con S. Breyer, disponible en: http://www.acslaw.org/node/3909 Debate del 5 de diciembre de 2006. 
para el que la única lectura posible es la que es capaz de descifrar la intención original del texto vinculándola a su mentor ${ }^{53}$.

El texto y sus significados históricos o intencionales ${ }^{54}$ por un lado, y el texto y sus expresiones o significados convencionales, por otro, formarían, sin embargo, dos manifestaciones de una misma concepción en la interpretación constitucional, en tanto dependientes de un texto. Por una parte, la interpretación se presenta como lectura literal (objetiva), por otra como lectura intencional (subjetiva). El convencionalismo lingüistico, no obstante, apostaría más bien por una asignación de significados que partiendo del texto, puede sin embargo, apartarse de una lectura literal en busca de consensos lingüísticos que contextualicen el significado ${ }^{55}$. De este modo, creo que en este esquema general el originalismo norteamericano estaría más cerca del textualismo literal subjetivo que de un textualismo convencional, que considera que en la interpretación de un texto, tanto vale la intención como las convenciones lingüísticas, que, en muchos casos incluso, puede imponerse en busca de un mínimo de racionalidad que exige la labor de interpretación ${ }^{56}$.

Un ejemplo puede ilustrar mejor esta perspectiva. En el caso Dred Scott (1857), la Corte Suprema de los Estados Unidos de Norteamérica, fiel a una concepción originalista se preguntó si un negro, "cuyos antepasados llegaron a este país para ser vendidos como esclavos, puede convertirse en un miembro de pleno derecho de la Comunidad política creada por nuestra Constitución y, por consiguiente, gozar de todos los derechos, libertades e inmunidades que esta garantiza", para responder en sentido negativo esta cuestión, la Corte asignó un significado "original" al concepto "ciudadano" como sinónimo de "pueblo". En tal sentido la Corte argumentó "este tipo de personas (sic) no están incluidas, y no estaba previsto que lo estuvieran, en el concepto constitucional de "ciudadanos" y, por consiguiente, no pueden válidamente reclamar ninguno de los derechos, libertades e inmunidades que la Constitución garantiza a los ciudadanos de los Estados Unidos. Al contrario, en el momento constituyente eran considerados una raza subordinada e inferior, bajo la autoridad de la raza dominante, $y$, en libertad o en esclavitud, continúan sometidas a ella (sic) y no tenían más derechos que los que las autoridades quisiesen otorgarles". Beltrán de Felipe, Miguel; Gonzales, Julio (2005). Las sentencias Básicas del Tribunal Supremo de los Estados Unidos de América. Madrid: Centro de Estudios Políticos y Constitucionales - BOE, pp. 145 y ss.

Dworkin ha propuesto una distinción más radical al referirse al originalismo "semántico", "que entiende que lo que colectivamente querian decir los legisladores es decisivo para la determinación del significado constitucional" y el originalismo de la "expectativa"; "para el que lo decisivo es qué esperaban conseguir al decir lo que dijeron". Dworkin, Ronald (2007). La justicia con toga. Traducción de Marisa Iglesias Vila e Ínigo Ortiz. Madrid: Marcial Pons, p. 143.

Aun cuando este es un problema irresuelto, como lo advirtiera el propio KeLSEN: "Pese a los esfuerzos de la jurisprudencia tradicional no se ha logrado resolver, en favor de uno u otro, en manera objetivamente válida el conflicto entre voluntad y expresión (...) Inclinarse a la voluntad supuesta del legislador, dejando a un lado el tenor literal, o bien atenerse estrictamente al tenor literal sin preocuparse por la voluntad -por lo general, problemática, del legislador- es, desde el punto de vista del derecho positivo, equivalente por entero". Kelsen, Hans (1979). Teoría Pura del Derecho. Traducción de Vernengo. México: UNAM, p. 352.

Un buen sector de la teoría jurídica analítica compartiría este punto de vista incluso desde una postura que se ha dado en llamar el positivismo inclusivo. Moreso, Josep Joan (2004). "El positivismo jurídico y la aplicación del Derecho". Doxa. No 27. 


\section{(2.2) EL JUEZ ESCÉPTICO Y LA INTERPRETACIÓN COMO "CREACIÓN" LIBRE}

En la famosa esquematización de Hart, esta sería cercana a la posición de la "pesadilla"57. "(...) El punto de vista de que los jueces siempre crean y nunca encuentran el derecho que imponen a las partes en el proceso". Si bien Hart intenta una "imagen" de lo que sucede en el mundo jurídico norteamericano, el realismo ha traspasado fronteras. La siguiente cita recoge con bastante elocuencia el sentido de esta postura: "Las reglas jurídicas no juegan ya el papel de instrumentos fiables que ayudan a los individuos a trazar, de manera precisa, las líneas según las cuales puedan organizar su conducta. Estas reglas se convierten más bien en instrumentos maleables que pueden plegarse a las estrategias y los intereses de cada jugador... el derecho no es lo que la ratio dice, tras un examen público del texto de la ley, sino lo que impone la voluntas de quien en cada ocasión tiene más poder sobre el lenguaje. El cosmos del derecho se rompe en una pluralidad indefinida de mundos, cada uno de los cuales obtiene, en definitiva, su propia legitimidad de los speech acts de los infinitos juegos del lenguaje, en el que los miembros de cada comunidad jurídica hacen estallar su fantasía hermenéutica" 58 .

Llevado al ámbito constitucional, esto supone asumir que la Constitución nada o poco le dice al Tribunal a la hora de interpretar sus cláusulas. El Tribunal es siempre libre al momento de interpretar la Constitución, la misma que, al final de cuentas, es "lo que los jueces dicen que es", en la famosa expresión del chief justice Hughes ${ }^{59}$. Es verdad que esta afirmación no puede ser entendida en clave normativa o prescriptiva, sino más bien como descriptiva de lo que suele suceder en la práctica, pero es verdad también que este es el argumento que mejor define y fundamenta el realismo constitucional ${ }^{60}$.

Si bien la imagen de la "pesadilla" ha sido expuesta para tratar de describir una cierta corriente de pensamiento norteamericano muy crítica del formalismo y escéptica respecto de los controles racionales a la actividad

57 Hart, H. L. A. (2000). "Una mirada inglesa a la teoría del derecho norteamericana: la pesadilla y el noble sueño". En Pompeau Casanovas / Moreso, J. J. (eds,). El Ambito de lo Jurídico. Barcelona: Editorial Crítica, pp. 327-350.

58 Vogliotti, M. (1997) "La bande de Möbius: Un modèle pour penser les repports entre le fait et le droit". Revue interdisciplinaire d'études juridiques, No 38, p. 106.

59 Hughes, Charles Evans (1971). La Corte Suprema de los Estados Unidos. México: FCE, p. 7.

60 Adopto este nomen iuris en clara alusión al realismo jurídico de procedencia norteamericana para referirme a una cierta actitud, a veces inconsciente, en la práctica de los tribunales constitucionales que suele sobreponer su poder a los propios mandatos del poder del pueblo constituyente, sobreestimando la labor de la concreción judicial y poniendo en serio riesgo por esta vía las bases conceptuales del modelo de la democracia representativa liberal para reemplazarla por una suerte de aristocracia judicial. 
judicial; pero es verdad también que, en la medida que el modelo del constitucionalismo se resuelve en términos prácticos como judicialismo ${ }^{61}$, conviene prevenirnos respecto de los límites a la actividad judicial, sobre todo cuando dicha actividad se desarrolla en el ámbito de la justicia constitucional, que a veces, inconscientemente, parece adoptar una suerte de realismo ingenuo, en la creencia que el único órgano con capacidad para crear Derecho definitivo, es el Tribunal Constitucional, o que todo lo que el Tribunal dice o crea se transforma sin más en "sustancia constitucional".

El escepticismo interpretativo tiene múltiples expresiones, por lo que conviene seguir el esquema analítico que ha planteado Moreso ${ }^{62}$. En tal sentido, las tesis atribuibles a esta perspectiva serían: a) Imposibilidad de conocer la verdad o falsedad de las proposiciones constitucionales (tesis metafísica); b) imposibilidad de asignar significados irrefutables a los enunciados constitucionales (tesis semántica); c) Imposibilidad de construir productos interpretativos verdaderos. Los significados (normas) no existen (tesis lógica); d) No existen respuestas correctas en los casos constitucionales (la tesis jurídica).

Una versión fuerte del escepticismo sería incompatible con cualquier esquema en el que se intente formular una teoría de la argumentación constitucional racional, en la medida que no sería posible incorporar criterios de corrección en la toma de decisiones. Sin embargo, desde una perspectiva de la argumentación racional, podría aceptarse la tesis jurídica de la imposibilidad de respuestas correctas, pero asumiendo como premisas algunas tesis diferentes a las establecidas en las tres tesis que anteceden a la tesis jurídica de la negación de una única respuesta en todo caso constitucional, como trataremos de ver más adelante. De este modo, el escepticismo puede resultar compatible en algunos puntos con teorías racionales de la argumentación.

La tesis de la interpretación escéptica o libre creación judicial, que se observa con claridad en el realismo norteamericano, no es, sin embargo una tesis teórica solo perceptible en el esquema estadounidense. Moreso ha introducido en su análisis dentro de esta perspectiva a una de las ver-

61 En este sentido, Luis Prieto, cuando afirma: "En resumen, el neoconstitucionalismo como modelo de organización jurídico polírica quiere representar un perfeccionamiento del Estado de Derecho, dado que si es un postulado de este el sometimiento de todo poder al Derecho, el tipo de Constitución que hemos examinado pretende que ese sometimiento alcance también al legislador. Bien es cierto que, a cambio, el neoconstitucionalismo implica también una apertura al judicialismo, al menos desde la perspectiva europea, de modo que si lo que gana el Estado de Derecho, por un lado, no lo quiere perder por el otro, esta fórmula política reclama, entre otras cosas, una depurada teoría de la argumentación capaz de garantizar la racionalidad y de suscitar el consenso en torno a las decisiones judiciales". Prieto SANCHís, Luis (2002) 89 (cursiva agregada). nal. Madrid: Centro de Estudios Políticos y Constitucionales, pp. 186-187. 
siones, hoy por hoy, de mucha influencia en la práctica de los tribunales constitucionales. Nos referimos a la corriente analítica que ha propuesto la distinción entre disposición y norma. Conforme a esta concepción, el objeto de la interpretación no son las normas, sino los enunciados lingüísticos, las grafías o textos con que se expresa el constituyente. La cuestión central aquí radica en establecer si los enunciados interpretativos (es decir, la justificación de los significados de un texto) pueden o no ser sometidos a control sobre su verdad o falsedad. Respondiendo de manera negativa esta cuestión, Moreso ha sostenido que "si la interpretación nunca tiene como resultado proposiciones susceptibles de verdad o falsedad y dado que las proposiciones jurídicas presuponen la actividad interpretativa -la atribución de significado a determinadas formulaciones normativas-, entonces la tesis lógica del escepticismo es adecuada y ello conlleva la tesis jurídica: nunca hay respuesta correcta para ningún caso, esto es, los jueces siempre crean y nunca aplican el derecho a los casos concretos"63.

Si bien es una afirmación que luego es sometida a crítica por el rector de la Universidad Pompeu Fabra, vale la pena dejar establecido que, en esencia, esta parece ser una descripción adecuada de lo que sucede en todo proceso de interpretación, en el que siempre es posible distinguir los actos de redacción, los de interpretación y los actos de aplicación del Derechoo ${ }^{64}$. De manera que los controles que se pueden establecer no están orientados a verificar la verdad o falsedad de los enunciados interpretativos que decodifican un texto, sino más bien, a buscar la adhesión del auditorio en base a una racionalidad limitada por el contexto, respecto de las posibilidades interpretativas que ofrecen la mejor solución a un problema concreto.

De este modo, la tarea se orienta a construir un modelo de argumentación más dialógica y menos depurada lógicamente, con incidencia en su aceptabilidad o razonabilidad, y ya no tanto en su armonía lógica. Aquí cabe la contraposición que propone Zagrebelsky en el contexto del moderno constitucionalismo entre scientia juris y juris prudentia: "la primera como racionalidad formal, la segunda como racionalidad material, es decir, orientada a los contenidos. (...) Mientras que el criterio que preside la primera es la oposición cualitativa verdadero-falso, todo-nada, el que preside la segunda es una progresión cuantitativa que va desde lo menos a lo más apropiado, desde lo menos a lo más oportuno, desde lo menos a lo más adecuado y productivo"65.

En sentido contrario parece manifestarse Stith cuando afirma que "Una interpretación es una fuente secundaria de información a la que recurrimos cuando no somos capaces de entender la fuente primaria por nuestros propios medios". En este sentido la "fuente primaria" sería objeto de un conocimiento limitado al que la interpretación le resulta no obstante prescindible (in claris non fit interpretatio). SтITH (2005) 162. 
La crisis de certeza en el Derecho, sin embargo, no puede conducirnos al escepticismo de no poder construir un modelo capaz de asumir los retos del modelo del constitucionalismo. El que alguien pueda juzgar un argumento como mejor que otro a partir de ciertos parámetros racionales, pone de manifiesto la posibilidad de límites a una creación interpretativa sin fronteras. De este modo, incluso en los procesos más volitivos o aparentemente libérrimos, siempre es posible un juicio externo a partir de criterios mínimos de corrección ${ }^{66}$. De este modo, Derecho válido no es todo que los tribunales dicen que es, al margen que por la fuerza institucional del Derecho, en un caso en concreto resulten aplicables.

En el fondo, sin embargo, los dos extremos expuestos hasta hora presentan paradójicamente similares signos de irracionalidad. La primera opción, por sobredimensionar el papel del autor de los textos y desestimar el protagonismo irreducible del juez o tribunal en los procesos de interpretación y aplicación del derecho; el segundo, en cambio, por convertir el derecho en un asunto de "brujas y unicornios" y por presentar al juez como un ser incontrolable en sus decisiones. Conviene por tanto identificar un punto medio.

\section{(2.3) JUEZ COMPROMETIDO CON LOS VALORES PERO LIMITADO POR LA ARGUMENTACIÓN RACIONAL}

Como lo han puesto de manifiesto Laurence Tribe y Michael Dorf ${ }^{67}$, "Así como la intención original de los primeros autores -incluso si pudiera ser capturado en un laboratorio, embotellado y cuidadosamente inspeccionado bajo un microscopio- no ofrece una interpretación determinada satisfactoria de la Constitución, también del otro lado del espectro debemos rechazar como completamente insatisfactoria la idea de una Constitución vacía o infinitamente maleable".

De este modo, ni el noble sueño, de quienes creen encontrar en la Constitución respuestas claras conforme a la "original intención" de sus autores, ni la pesadilla de quienes creen que la Constitución es solo un pretexto para hacer con ella lo que uno anhela, pueden considerarse como modelos aceptables de interpretación constitucional. En consecuencia, también el profesor Tribe cree que "debemos encontrar los principios de interpretación que puedan anclar la Constitución en alguna realidad externa más segura y determinada". No obstante, una tercera opción solo es posible si aceptamos la actividad interpretativa como actividad de creación, pero sometida a ciertos controles de racionalidad.

66 
Aunque Hart ha puesto a Dworkin en el casillero de los "sońadores" 68 , creo que sus aportes nos acercan a lo que puede ser la "tercera vía” en esta búsqueda. De otro lado, las teorías de la argumentación racional que se han desarrollado hacia finales del siglo XX, sobre todo en Europa, permiten aproximarnos a un modelo racional de argumentación que no niega, desde el inicio, que interpretar es crear y que, en consecuencia, argumentar desde una Constitución de principios y valores, supone construir soluciones que no preexisten a los casos.

Como bien lo ha puesto de manifiesto recientemente García Figueroa, "desde una concepción constructivista, el discurso práctico (del que el jurídico aquí se presupone es un caso especial -sonderfallthese-) se construye y no preexiste a la actividad discursiva de los participantes en él"69.

¿Es el constructivismo la tercera vía? Las propuestas del constructivismo alcanzan a toda una tradición filosófica a la que no es posible remitirnos por ahora ${ }^{70}$. Baste con dejar anotado, el hecho cada vez más aceptado, de que en los actuales sistemas jurídicos no es posible asumir la idea de un sistema cerrado de proposiciones normativas no derrotables, esto es, que los casos más trascendentes que llegan a los tribunales, configuran, por lo general, una especie de casos para los que no ha sido posible generalizar una solución ex ante o, en otros supuestos, se trata de situaciones en las que el derecho preexistente resulta "derrotable" frente a la fuerza de las razones. En consecuencia, tanto la generalización (universalidad) como la certeza del Derecho están en cuestión. Se trata entonces de que las respuestas a los casos hay que construirlas basándonos en alguna idea de corrección externa y no dependiente del sistema normativo preexistente, sino, en último caso, a partir de algún sistema moral: en buena cuenta se trata de asumir que el discurso jurídico es una especie del discurso moral práctico ${ }^{71}$.

Esta es también la idea que ha defendido, según creo comprender,

68 A esta conclusión llega Hart, porque considera que "Para Dworkin, incluso en el más difícil de los casos difíciles, en el cual dos interpretaciones alternativas de una disposición o dos reglas en conflicto parecen adecuarse igualmente bien al derecho establecido previamente, el juez nunca crea derecho". Hart (2000) 342. Propongo, sin embargo, que dejemos por ahora la propuesta de la "única respuesta correcta" y rescatemos de Dworkin las críticas al originalismo y su teoría de la interpretación.

69 García Figueroa, Alfonso (2009). "Neoconstitucionalismo y ponderación", en Ortega, Luis y De la Sierra, Susana: Ponderación y derecho administrativo, Madrid: Marcial Pons, p. 93.

70 Para una recontrucción de la tradición filosófica con especial referencia al procedimentalismo, me remito al texto de Massini Correas, Carlos (2004). Constructivismo ético y justicia procedimental en John Rawls, Mexico: Universidad Nacional Autónoma de México. También puede verse al respecto el texto de Nino, Carlos S. (1989). El constructivismo ético, Madrid: Centro de Estudios Políticos y Constitucionales.

71 La comprensión de la argumentación jurídica como discurso moral propuesta por Alexy apunta en esa dirección. Alexy (1999). 
Dworkin en la disputa con el originalismo, al reclamar una actitud de compromiso con los valores constitucionales, proponiendo una lectura moral de la Constitución ${ }^{72}$. "La lectura moral -a decir de este autor- insiste que la Constitución significa lo que los constituyentes intentaron decir. El originalismo insiste en que significa lo que estos esperaban que su lenguaje significaría"73. Si comprendo de manera correcta, una lectura moral supone, en primer lugar, asumir que el punto de partida del proceso interpretativo tiene que ver con enunciados de tipo moral contenidos en la Constitución. Los derechos fundamentales son "compromisos morales" dirá Dworkin, por lo que asumir una lectura moral supone, más que interpretar un texto, descifrar ciertos conceptos, sin que ello signifique reivindicar las "concepciones" que llevaron a sus autores a redactarlos en determinado momento ${ }^{74}$.

De este modo, los redactores del texto constitucional en tanto "prudentes estadistas", apelaron a la abstracción de los conceptos, porque se proponían redactar una Constitución "a partir de principios morales abstractos, no de encriptadas referencias a sus propias opiniones (o las de sus coetáneos) sobre la mejor forma de aplicar tales principios"75.

De manera que una forma de ser fiel a los estadistas que redactaron la Constitución sería también asumiendo los compromisos morales que ellos nos platearon, pero contextualizándolos en el momento en que dichos compromisos deben ser asumidos. A eso apunta Dworkin cuando propone la distinción entre concepto y concepción. El concepto es indispensable, pues sin él no existe la comunidad a la que dirigen los mensajes de la Constitución. Como nos lo ha hecho notar Marisa Iglesias, "el concepto indica algo sobre el mundo, no sobre las palabras", de manera que "el concepto no tiene carácter semántico, sino interpretativo. Podría decirse que es el juicio o la idea más abstracta acerca de cuál es la mejor forma de presentar un fenómeno, cuyo acierto o cuya verdad es incontrovertible en un determinado contexto discursivo y en un tiempo dado"76.

Las concepciones, en cambio, son las diferentes formas en que puede ser reconstruido un concepto en un determinado caso o en un tiempo y espacio determinados. Así, mientras los conceptos requieren unidad, pues de lo contrario nadie los identificaría como tales, las concepciones tienden a ser controvertidas. Podríamos así decir, que los conceptos sirven

Dworkin, Ronald (2002). "La lectura moral de la Constitución y la premisa mayoritaria". Cuestiones Constitucionales, pp. 3 y ss.

73 DWORKIN (2002) 19.

74 Dworkin, Ronald (2002). Los derechos en serio. Barcelona: Ariel, 508 pp.

75 DWORKIN (2007) 140.

76 Iglesias Vila, Marisa (1999). El problema de la discrecionalidad judicial. Una aproximación al conocimiento juridico. Madrid: Centro de Estudios Políticos y Constitucionales, p. 137. 
a la hora de generalizar, las concepciones son indispensables a la hora de particularizar o de concretar los mensajes conceptuales.

Me parece que la distinción entre concepto y concepción constituye un buen punto de partida para comprender el rol de la interpretación constitucional en el contexto de las actuales sociedades en las que rige el principio jurídico del pluralismo. El pluralismo requiere ser incorporado en los procesos de interpretación, los cuales se muestran ya no como una estrategia orientada a desencriptar textos del pasado, sino más bien como una reacción a partir de nuestras experiencias y necesidades ${ }^{77}$. La distinción entre concepto y concepción constituye también una forma de introducir las exigencias del caso en los procesos de interpretación.

En efecto, los problemas de interpretación constituyen siempre (a menos que se traten de meras especulaciones teoréticas de los juristas) disputas frente a casos concretos. Esta elemental constatación muestra también que el caso es el que orienta y a veces "moldea" la solución interpretativa. Creo que en esta dirección Zagrebelsky ha dado un paso más en la propuesta de Dworkin al plantear la necesidad de la asignación de "sentido" y de "valor" en la interpretación de los casos como antesala o, mejor aún, como contrapartida a todo proceso de interpretación normativa. El sentido orienta la acción humana hacia un "resultado" social, mientras que la asignación de valor se ve condicionada por dicho sentido ${ }^{78}$.

La construcción de sentido y de valor da cuenta de la posibilidad de la objetividad en los juicios interpretativos y alejan las sospechas de subjetividad y el de incurrir en la "pesadilla" a la que alude Hart en su famoso ensayo. Pero también, por otro lado, la posibilidad de leer los contenidos morales de la Constitución a partir de las exigencias que plantean los casos nos muestra que los argumentos de Dworkin no pueden ser desaprovechados acusándolo de ser un "soñador" ingenuo, por el solo hecho de haber planteado el ideal regulativo de la única respuesta correcta ${ }^{79}$.

Al parecer, la mayor contribución de Dworkin, al menos con relación a la interpretación de la Constitución, no radica en la tesis de la

Una estrategia orientada a recoger, en la práctica de la interpretación constitucional, el mandato del pluralismo ha sido sugerida por Stith, quien luego de afirma que "Ningún tribunal debería poseer la facultad de imponer interpretaciones politizadas del derecho a toda una nación", ha sugerido la tesis conforme a la cual "...el poder de interpretar y aplicar la constitución y las leyes se debe otorgar a un número de instituciones jurisdiccionalmente distintas. De este modo, la multiplicidad de intérpretes contribuye a preservar el pluralismo en el pensamiento jurídico, una libertad frente a la dominación de cualquier ideología jurídica". STITH (2005) 180.

78 Zagrebelsky (2005) 137.

79 Puede resultar paradójico que el potencial argumentativo de DwORKIN sobre el activismo judicial y las posibilidades de lecturas alternativas al texto constitucional terminen finalmente en una formulación tan insostenible como el de la única respuesta, pero creo que el propio Dworkin se ha encargado de atenuar sus iniciales planteamientos sobre esta tesis. DWORKIN (2007) 52 - 54. 
única respuesta correcta, sino en habernos mostrado, sin sobrecogimientos, que la tarea de interpretar una Constitución que contiene derechos supone asumir compromisos y convicciones morales, y en mostrarnos que los desacuerdos en esta tarea no son ni metodológicos ni lingüísticos, sino básicamente se tratan de desacuerdos sobre nuestras concepciones acerca de lo que entendemos como bueno o malo en un determinado momento.

Una adecuada teoría de la interpretación supone, entonces, mostrar cuál es la mejor lectura moral en un tiempo y lugar determinado, una lectura que, llegado el caso, como lo plantea el propio Dworkin, "cuando no haya manera de reconciliar el texto y la práctica en una interpretación constructiva (...)" puede incluso "(...) desbancar a una pieza tan básica de los elementos interpretativos como el texto de la Constitución" 80 . Creo que aquí se da la vinculación entre la teoría moral de la interpretación y las exigencias de corrección en el razonamiento interpretativo: la posibilidad de que la argumentación racional, aun cuando Dworkin no lo plantee en estos términos, pueda derrotar la propia "claridad" de los textos normativos. Interpretar la Constitución supone entonces encontrar su sentido más racional a la luz de los casos que plantea la practica social.

De este modo, sin embargo, si bien se está ante un juez más comprometido con los valores que con los textos, el propio Dworkin reconoce que también se asume el riesgo de un juez con poderes peligrosamente ilimitados ${ }^{81}$. Como lo ha hecho notar Luis Prieto ${ }^{82}$, si bien esta manera de comprender la labor judicial resulta paradójica, si se toma en cuenta los demás postulados de la teoría del Derecho de Dworkin, queda claro que el compromiso con los mandatos morales de la Constitución requiere no solo de "un Tribunal activista, en el sentido de que debe estar preparado para formular y resolver cuestiones de moralidad política"83, sino, además, una teoría del razonamiento y de la argumentación que sea capaz de poner unos límites más o menos razonables, ahí donde el Derecho deja a la moral en una suerte de "tierra de nadie". En suma, una cierta capacidad para comprender los valores de una Constitución que se muestra "abierta" pero que impone contenidos sustanciales a los poderes llamados a actuar bajo su mandato ${ }^{84}$.

Lo que sigue de aquí en adelante impone la necesidad de indagar en

"Aunque la queja familiar de que la lectura moral da a los jueces un poder ilimitado es hiperbólica, contiene suficiente verdad para alarmar a aquellos quienes creen que tal poder judicial es inconsistente con una forma republicana de gobierno". DWORKIN (2002) 17. Prieto Sanchís, Luis (1985). "Teoría del Derecho y Filosofía Política en Ronald Dworkin". Revista Española de Derecho Constitucional, No 14.

83. DWORKIN (2002) 231.

84

Sin que desde luego ello implique, como bien lo ha hecho notar el profesor Díaz Revorio, incurrir en el peligroso desvío de "constituzionalizar" los propios valores del juez". DíAz Revorio, Francisco Javier (2004). La Constitución abierta y su interpretación, Lima: Palestra 178. 
el desarrollo de las teorías de la argumentación que, en los últimos años, han construido un importante arsenal para mitigar de algún modo las angustias de quienes creen que la lectura moral abre camino a un activismo sin fronteras hasta convertir a la democracia constitucional en una suerte de dictadura de los jueces. Ello, sin embargo, nos convoca a nuevas indagaciones que deben esperar por ahora.

\section{BIBLIOGRAFÍA}

- Aguiló Regla, Josep (2004). La Constitución del Estado Constitucional. Lima-Bogotá: Palestra, Temis.

- Alexy, Robert (1999). "La tesis del caso especial", Isegoría, No 21.

- _ (2003). "Los derechos fundamentales en el Estado constitucional democrático". Traducción de Alfonso García Figueroa. En Carbonell Miguel (editor) Neoconstitucionalismo(s). Madrid: Trotta.

- Alonso García, E. (1984). La interpretación de la Constitución. Madrid: Centro de Estudios Políticos y Constitucionales.

- Atienza Rodríguez, Manuel (2007). "Constitución y argumentación". Anuario de Filosofía del Derecho, No 24.

- Bayon, Juan Carlos (2004). "Democracia y derechos. Problemas de fundamentación del constitucionalismo". En AA. Vv. Constitución y Derechos Fundamentales. Madrid: Centro de Estudios Políticos y Constitucionales.

- Beltrán de Felipe, Miguel Gonzales, Julio (2005). Las sentencias Básicas del Tribunal Supremo de los Estados Unidos de América. Madrid: Centro de Estudios Políticos y Constitucionales - BOE.

- Cappelletti, M. (1986). “¿Renegar de Montesquieu? La expansión y la legitimidad de la "justicia constitucional". Revista Española de Derecho Constitucional, No 17.

- Carbonell Sánchez, Miguel (2007). Teoría del neoconstitucionalismo: ensayos escogidos, Madrid: Trotta.

(1997). Democracia y desconfianza. Una teoría del control Constitucional. Bogotá: Siglo del Hombre Editores - Universidad de los Andes.

- Díaz Revorio, Francisco (2004). La Constitución abierta y su interpretación, Lima: Palestra.

- Dworkin, Ronald (2007). La justicia con toga. Traducción de Marisa Iglesias Vila e Ínigo Ortiz. Madrid: Marcial Pons.

- (2002). "La lectura moral de la Constitución y la premisa mayoritaria". Cuestiones Constitucionales.

(2002). Los derechos en serio. Barcelona: Ariel.

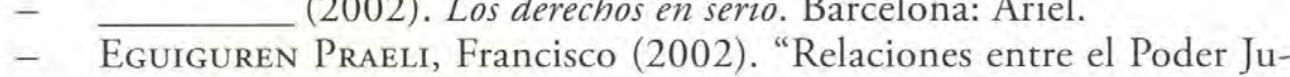
dicial y el Tribunal Constitucional en el Perú", en él mismo: Estudios Constitucionales. Lima: ARA 
- Ely, John (1980). Democracy and distrust. A theory of judicial review. Harvard University Press, 1980.

- Ferrajoli, Luigi / Moreso, Josep / Joan Atienza Rodríguez, Manuel (2008). La teoría del derecho en el paradigma constitucional. Madrid: Fundación Coloquio Jurídico Europeo.

- Gadamer, Hans-Georg (1977). Verdad y método. Salamanca: Ed. Sigueme.

- García Amado, Juan A. (2003). "Sobre la interpretación Constitucional”. Ensayos de Filosofía jurídica, Bogotá: Temis.

- García Amado, Juan A. (2004). "La interpretación constitucional". Revista Jurídica de Castilla y León, No 2, pp. 35 y ss.

- García Amado, Juan A. (2007). "Derechos y pretextos. Elementos de crítica del neoconstitucionalismo". En Carbonell, Teoría del neoconstitucionalismo: ensayos escogidos, Madrid: Trotta.

- García Belaunde, Domingo (2007). "¿Guerra de las Cortes? A propósito del proceso competencial entre el Poder Ejecutivo y el Poder Judicial". Cuadernos de análisis y crítica a la jurisprudencia constitucional, No 4, Lima: Palestra Editores.

- García de Enterría, E. (1981). "La posición jurídica del Tribunal Constitucional en el sistema español: posibilidades y perspectivas". $R e-$ vista Española de Derecho Constitucional, vol. 1, Núm. 1, enero-abril.

(1983). La Constitución como norma y el Tribunal Constitucional, $3^{a}$ edición, Madrid: Civitas

- García Figueroa, Alfonso (2009). "Neoconstitucionalismo y ponderación", en Ortega, Luis y De la Sierra, Susana: Ponderación y derecho administrativo, Madrid: Marcial Pons.

- Garrido Falla, F. (2002). "La elaboración de las sentencias del Tribunal Constitucional: una experiencia personal". Teoría y realidad constitucional, UNED.

- Grández Castro, Pedro (2006). "Tribunal Constitucional y transición democrática. Un ensayo de interpretación de su actuación”. Gaceta Constitucional No 4, Lima: Tribunal Constitucional. Disponible en http://www.tc.gob.pe/gaceta

- Guastini, Ricardo, (2007). Teoría e ideología de la interpretación constitucional, Traducción de Miguel Carbonell y Pedro Salazar, Madrid: Trotta.

- Häberle, Peter (2001). "La jurisdicción constitucional institucionalizada en el Estado Constitucional”. Traducción de Joaquín Brague Camazano. Anuario Iberoamericano de Justicia Constitucional. № 5 , Madrid.

- Hamilton, Alexander (2000). Paper No LXXVIII. El Federalista, FCE.

- Hart, H. L. A. (2000). "Una mirada inglesa a la teoría del derecho norteamericana: la pesadilla y el noble sueńo". En Pompeau Casano- 
vas y Josep J. Moreso (eds.): El Ambito de lo Jurídico. Barcelona: Editorial Crítica.

- Hughes, Charles Evans (1971). La Corte Suprema de los Estados Unidos. México: FCE.

- Iglesias Vila, Marisa (1999). El problema de la discrecionalidad judicial. Una aproximación al conocimiento jurídico. Madrid: Centro de Estudios Políticos y Constitucionales.

- Jestaedt, Matthias (2008). "El Derecho Público: una ciencia". En Eduardo Montealegre (coord.): La ponderación en el Derecho. Bogotá: Universidad Externado de Colombia.

- Kelsen, Hans (1979). Teoría Pura del Derecho. Traducción de Vernengo. México: UNAM.

- Landa Arroyo, César (2006). "La autonomía procesal del Tribunal Constitucional”. Justicia Constitucional, ańo II, No 4, Lima.

(2007). Tribunal Constitucional y Estado Democrático. Tercera Edición, Lima: Palestra.

- Mendoza Escalante, Mijail (2007). Conflictos entre derechos fundamentales: expresión, información y honor. Lima: Palestra Editores.

- Moreso Josep Joan (1997). La indeterminación del Derecho y la interpretación constitucional. Madrid: Centro de Estudios Políticos y Constitucionales.

cho". Doxa, No 27.

(2004). "El positivismo jurídico y la aplicación del Dere-

- Nino, Carlos S. (1989). El constructivismo ético, Madrid: Centro de Estudios Políticos y Constitucionales.

- Pegoraro, Lucio. "La utilización del derecho comparado por parte de las Cortes Constitucionales: un análisis comparado. Disponible en: http://www.iustel.com/v2/revistas/detalle_revista.asp?id... [Fecha de visita 10 de septiembre de 2009].

- Pérez Luño, Antonio (1984). Derechos humanos, Estado de Derecho y Constitución. Madrid: Tecnos.

- Pogge, Thomas (2005). La pobreza en el mundo y los derechos humanos. Barcelona: Paidós.

- Prieto SANchís, Luis (1987). Ideología e interpretación jurídica, Madrid: Tecnos.

(1985). "Teoría del Derecho y Filosofía Política en Ronald Dworkin". Revista Española de Derecho Constitucional, No 14.

(2002). Derechos fundamentales, neoconstitucionalismo $y$ ponderación judicial, Lima: Palestra.

- (2004.) "El constitucionalismo de los derechos". Revista Española de Derecho Constitucional, No 71.

(1999). Constitucionalismo y positivismo. México: Fontamara.

- Sager, L. G. (2004). Juez y Democracia. Una teoría de la prácti- 
ca constitucional norteamericana. Traducción de Víctor Ferreres Comella. Madrid: Marcial Pons.

- Sastre Ariza, Santiago (1999). Ciencia jurídica positivista y neoconstitucionalismo. Madrid: McGraw-Hill Interamericana de Espańa.

- Shapiro, M. (2008). "Revisión Judicial en democracias desarrolladas". En: Tribunales Constitucionales y democracia. México: Suprema Corte de Justicia de la Nación.

- Spadaro, Antonio (2007). "Las motivaciones de las sentencias de la Corte como "técnica" de creación de normas constitucionales". Palestra del Tribunal Constitucional, año 2, № 12, Lima: Palestra Editores.

- Stith, Richard (2005). "Imperio del Derecho versus Imperio de los Jueces: un alegato por el pluralismo jurídico". Revista de Derecho Universidad Católica del Norte, año 12, No 1, pp. 157 - 182.

- Tribe, Lawrence Dorf, Michael (1991). On reading the Constitucion. Harvard University Press.

- Viehweg, Theodor (1964). Tópica y jurisprudencia. Traducción de Luis Díez-Picazo. Madrid: Taurus.

- Vogliotti, M. (1997). "La bande de Möbius: Un modèle pour penser les repports entre le fait et le droit". Revue interdisciplinaire d'études juridiques, No 38.

- Waldron, Jeremy (2005). Derecho y Desacuerdos. Traducción de J. L. Martí y Á. Quiroga. Madrid: Marcial Pons.

- Zagrebelsky (2008). Principios y votos. El Tribunal Constitucional y la política. Traducción de Manuel Martínez Neira. Madrid: Trotta. (2005). El Derecho dúctil. Ley, derechos justicia. Traducción de Marina Gascón. Sexta edición. Madrid: Trotta. 